\title{
Temuan insidental lesi radiopak asimptomatik pada pemeriksaan radiografi panoramik: laporan 3 kasus dan ulasan pustaka Dense Bone Island(DBI)
}

\author{
Fadhlil Ulum Abdul Rahman ${ }^{1 *}$, Lusi Epsilawati², Farina Pramanik ${ }^{2}$, Mirna Febriani $^{3}$
}

\begin{abstract}
Objectives: Dense Bone Island (DBI) is one of the lesions that are usually visualized on a panoramic radiographs in the form of total radiopaque in the periapical area of the mandibular premolar or molar but most of them are not directly related to the dentition. This case report is aimed to give summaries about the description of 3 DBI cases.
\end{abstract} patients with asymptomatic well-defined damage the surrounding teeth lead to the diagnosis radiopaque lesions which was found incidentally in of dense bone island. the periapical area of the left mandibular first

premolar with two of them showing the lesions located exactly in the 1/3 apical of the root and one of them seen as root resorption like. From clinical information, all three cases reported no clinical symptoms and affected teeth are still vital.

Conclusion: Incidental findings of well-defined radiopaque lesion in the periapical area of the

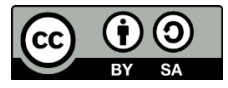

This work is licensed under a Creative Commons Attribution 4.0
${ }^{1}$ PPDGS Radiologi Kedokteran Gigi, Fakultas Kedokteran Gigi, Universitas Padjadjaran, Bandung, Indonesia, 40132

${ }^{2}$ Departemen Radiologi Kedokteran Gigi, Fakultas Kedokteran Gigi, Universitas Padjadjaran, Bandung, Indonesia 40132

${ }^{3}$ Departemen Dental Material, Fakultas Kedokteran Gigi, Universitas Prof. Dr. Moestopo (Beragama), Jakarta, Indonesia, 12330

*Correspondence to:

Fadhlil Ulum Abdul Rahman

■fadhlilpunyaemail@gmail.com

Received on: June 2019

Revised on: July 2019

Accepted on: August 2019
Keywords: Dense Bone Island, asymptomatic radiopaque lesions, panoramic radiograph

Cite this article: Rahman FUA, Epsilawati L, Pramanik F, Febrian M. Temuan incidental lesi radiopak asimptomatik pada pemeriksaan radiografi panotamik: laporan 3 kasus dan ulasan Pustaka Dense Bone Island (DBI). Jurnal Radiologi Dentomaksilofasial Indonesia 2019;3(2):35-40. https://doi.org/10.32793/ jrdi.v3i2.488

\section{PENDAHULUAN}

Lesi radiopak asimptomatik seringkali ditemukan secara insidental ketika dilakukan pemeriksaaan radiografi rutin untuk kebutuhan tertentu. Dense Bone Island (DBI) adalah salah satu lesi asimptomatik yang hampir sebagian besar kasusnya ditemukan secara insidental tersebut. Sisman et al. meneliti prevalensi dan frekuensi kejadian DBI di Turki dengan menggunakan 2.211 radiograf panoramik menghasilkan angka prevalensi sebesar 6,1\%, kemudian Tolentino et al. pada tahun 2014 di Brazil menghasilkan angka prevalens kejadian lesi ini sebesar 5,6\% dari 354 pasien, angka yang tidak jauh berbeda disampaikan Farhadi et al. pada tahun 2016 di Iran pada persentase sebesar 7,5\% dari 411 pasien dan sedangkan Syed et al. pada tahun 2017 dalam penelitiannya menghasilkan prevalensi kemunculan lesi ini sebesar 3,2\% dari total 4581 pasien. $^{1-4}$ Walaupun frekuensi kejadian DBI terhitung cukup kecil (uncommon) berdasarkan berbagai penelitian yang telah dilakukan, pengetahuan tentang ciri radiografis dari lesi ini sangat penting untuk dimiliki oleh seorang klinisi agar dapat mengidentifikasi dan menegakkan diagnosis yang adekuat jika lesi ini ditemukan pada radiograf. Hal ini yang menjadi tujuan dari penulisan laporan kasus dan ulasan pustaka ini.

DBI pertama kali diperkenalkan oleh McDonnel et al. pada tahun 1993 dan seringkali disinonimkan dengan enostosis/endostosis, osteosklerosis, osteosklerosis periapikal idiopatik, bone scar, bone whorl, bone sclerosis, focal periapical osteopetrosis, dan bone eburnation. ${ }^{5-9} \mathrm{DBI}$ didefinisikan sebagai perubahan atau pembesaran tulang trabekular non ekspansif dan termasuk ke dalam lesi hiperplasia tulang, walaupun pada beberapa literatur menjadikan lesi ini segolongan dengan tumor jinak.

Hampir sebagian besar kasus DBI atau lesi osteosklerosis periapikal idiopatik ditemukan secara insidental pada pemeriksaan radiografi rutin seperti radiograf periapikal dan panoramik yang dilakukan untuk kebutuhan diagnosis keluhan yang lain. ${ }^{6,10,11}$ Etiologi dan asal dari lesi ini masih belum jelas, tetapi diduga adanya keterlibatan tekanan internal dan dibantu suplai darah yang memadai pada pembentukan massa tulang pada rahang khususnya mandibula. ${ }^{6}$

Beberapa literatur menyebutkan bahwa lesi ini adalah bentuk variasi anatomis dari perkembangan intraosseus dan seharusnya berada pada klasifikasi yang berbeda dengan lesi-lesi radiopak lain yang merupakan kasus-kasus akibat adanya inflamasi, proses displasia, neoplasma, keterlibatan manifestasi penyakit sistemik, dan berhubungan dengan beberapa perluasan lesi ke arah kortikal. 4,12

Secara mekanisme penyakit, lesi ini merupakan pertumbuhan terlokalisir dari tulang kompakta di dalam struktur tulang trabekula/kanselus sehingga terjadi pelebaran tulang trabekula dan meluas 


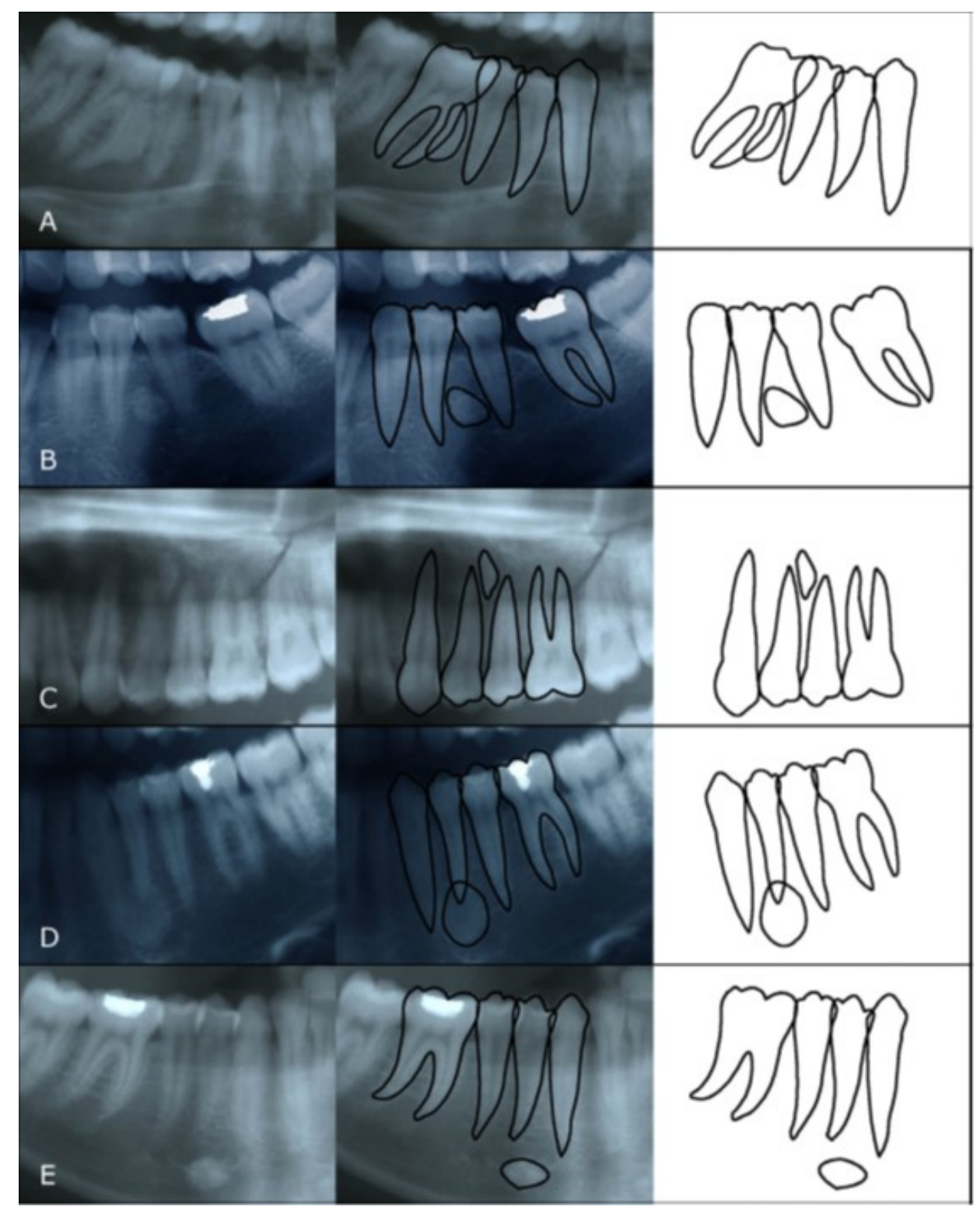

Gambar 1. Klasifikasi lesi Dense Bone Island (DBI) berdasarkan lokasi spesifik ${ }^{4}$

hingga ruang medular. Kemunculan lesi ini bersifat sklerotik soliter yang lebih banyak muncul pada akhir dekade pertama hingga dekade dua kehidupan sehingga lebih sering ditemukan pada orang dewasa daripada anak-anak. Walaupun begitu beberapa penelitian menyebutkan bahwa lesi ini mulai berkembang pada masa remaja awal. Literatur tedahulu menyebutkan tidak ada predileksi jenis kelamin terkait kemunculan lesi ini tetapi penelitian oleh Chintala et al. pada tahun 2017 dan Jimenez-Farfan et al. pada tahun 2018 menunjukkan prevalensi lesi pada wanita lebih banyak, dan telah dilaporkan bahwa lesi ini banyak ditemukan pada populasi Asia. ${ }^{5,9,11,13-15}$

Lokasi DBI seringkali ditemukan pada processus alveolaris pada rahang dan lebih sering pada area mandibula daripada maksila. Secara spesifik dapat berhubungan langsung dengan apikal akar gigi, di antara akar dua gigi maupun di antara gigi, khususnya pada area premolar dan molar. ${ }^{1}$ Berdasarkan lokasi kemunculannya, lesi ini diklasifikasi menjadi lima yaitu tipe interadikuler berupa area sklerotik terbatas di antara akar gigi dan saling terkait dengan lamina dura dari gigi yang berdekatan, tipe interadikuler dan terpisah dengan daerah sklerotik dibatasi antara akar gigi dan tidak saling terkait dengan lamina dura dari gigi yang berdekatan, tipe apikal dan interadikuler jika area radiopak berada di apeks akar dan menunjukkan perluasan yang signifikan di antara akar gigi, tipe apikal jika lesi terletak tepat pada apeks akar, dan tipe terpisah jika lesi terletak jauh dari apikal gigi dan jelas terpisah dari gigi dan lamina dura. 4,6,15

Dalam klasifikasi yang lain oleh Misirlioglu et al. mengelompokkan lesi ini ke dalam dua jenis berdasarkan keterkaitannya dengan kanalis mandibularis yaitu kelompok terpisah dari kanalis mandibularis dan kelompok terkait kanalis mandibularis. Kelompok terpisah dari kanalis mandibularis dibagi lagi menjadi empat jenis yaitu yang terkait dengan tulang kortikal bukal, tulang kortikal lingual, terkait bukal-lingual, dan terpisah 
dari kortikal bukal-lingual. Kelompok terkait kanalis mandibularis juga dibagi menjadi empat jenis. Hubungan dengan kanalis mandibularis lebih dapat diperiksa melalui radiografi cone beam computed tomography (CBCT). ${ }^{6}$

Seperti telah disebutkan sebelumnya bahwa les ini bersifat asimptomatik, sehingga sama sekali tidak ada gejala penyerta yang menandai adanya lesi ini dan tentu saja pasien tidak menyadarinya sebelum dilakukan pemeriksaan radiografi. Secara klinis gigi premolar dan molar yang terlibat baik secara langsung maupun tidak langsung tidak ada kelainan patologis. Jika dilakukan pemeriksaan histopatologis lesi ini akan menunjukkan jaringan padat terkalsifikasi tanpa ruang sumsum. ${ }^{6,8,9,16}$

Secara radiografis, lesi ini biasanya berbentuk membulat, sedikit lebih lonjong, atau bahkan tidak beraturan dengan ukuran yang bervariasi pula antara $2 \mathrm{~mm}$ sampai $1-2 \mathrm{~cm}$. Lesi ini well-defined terhadap tulang di sekitarnya walaupun pada sedikit kasus tampak menyatu dengan trabekula tulang sekitarnya. Lesi ini tidak terkait keberadaan gigi walaupun lokasinya dapat berhubungan dengan gigi. Tidak ada margin radiolusen maupun kapsu yang tampak membatasi lesi ini dengan tulang. Lesi ini biasanya soliter terlokalisir walaupun pada kasus tertentu pasien memiliki lesi jamak. Struktur internal dari lesi ini tampak radiopak homogen tanpa pola yang khas, tetapi kadang pula muncul bidang-bidang yang sedikit radiolusen tergantung pada bentuk dan ketebalan densitas lesi. Efek DBI terhadap jaringan sekitar tidak banyak dilaporkan, pada kasus yang jarang lesi ini dapat terletak tepat pada periapikal akar gigi dan tampak dikaitkan dengan resorpsi eksternal pada akar. Gigi yang terlibat selalu berada dalam keadaan vital dan jika terjadi resorpsi akar biasanya akan bersifat selflimiting. Dalam kasus sangat langka, lesi ini dapat menghambat erupsi dan terkait dengan kelainan bentuk akar seperti yang dilaporkan oleh Oshima et al. serta kadang dapat pula menyebabkan perpindahan gigi. Penelitian-penelitian terbaru juga mengarahkan keberadaan lesi ini dengan kondisi kelainan yang bisa terjadi pada area rongga mulut seperti impaksi kaninus walaupun hasilnya masih kurang signifikan. Lesi ini lebih sering statis dalam perkembangannya tetapi dapat meningkat ukurannya terutama pada masa aktif pertumbuhan rahang. Jika lesi ini muncul secara jamak lebih dari lima maka hubungan dengan familial adenomatous polyposis seperti sindrom Gardner perlu dipertimbangkan. Selain itu lesi jamak DBI juga perlu penelusuran riwayat keluarga tentang adanya kecenderungan kanker intestinum. ${ }^{6,9,11,14}$

Beberapa diagnosis banding dapat dipertimbangkan ketika menemukan lesi radiopak dengan gambaran radiografis seperti DBI. Periapical osseus dysplasia yang sudah maturasi dapat dibedakan dari lesi ini dengan adanya tepi radiolusen dan lebih sering melibatkan beberapa gigi vital pada bagian anterior. Ketika DBI terletak tepat pada apeks akar mungkin akan menyerupai sclerosing osteitis, dapat dibedakan dengan melihat keterlibatan gigi yang telah nonvital dan terinfeksi berupa adanya karies atau restorasi besar pada mahkota serta pelebaran membran periodontal di periapikal. Lesi ini juga bisa menyerupai sementoblastoma jinak dan hipersementosis, tetapi dapat dibedakan dari adanya lapisan tipis radiolusen pada perifer keduanya Sementoblastoma juga biasanya melibatkan pembengkakan ridge alveolar. Torus dan eksostosis juga secara radiografis mirip tetapi secara klinis lebih dapat dipalpasi, lesi DBI juga dianggap sebagai bentuk eksostosis internal. ${ }^{8,9,17}$

Untuk dapat menegakkan radiodiagnosis dari suatu lesi radiopak asimptomatik DBI terdapat beberapa ciri-ciri yang perlu diperhatikan berdasarkan rekomendasi MacDonald dan Janksowski yaitu asimptomatik; bukan lesi mixed radiolusen-radiopak dengan penampilan lesi fibroosseous atau odontoma; tidak terkait langsung dengan karies atau restorasi besar; bukan penebalan lamina dura; tidak dikelilingi oleh lingkaran haloradiolusen; tidak terkait dengan resorpsi gigi yang berdekatan; tidak ada bukti perpindahan kanal alveolar inferior, lantai sinus maksilaris atau gigi yang berdekatan dengan lesi; menunjukkan lesi yang tidak ekspansif; juga ketika sisa-sisa gigi sulung atau permanen telah diidentifikasi secara jelas dan dikeluarkan dari diagnosis serta tidak khas dari kondisi lainnya. ${ }^{3}$ Adapun karena lesi ini asimptomatik maka secara umum tidak memerlukan perawatan apapun.

\section{LAPORAN KASUS}

Pada artikel ini dilaporkan tiga kasus temuan insidental berupa lesi radiopak asimptomatik pada radiograf panoramik. Kasus pertama seorang pasien perempuan berumur 20 tahun mendatangi klinik konservasi gigi Rumah Sakit Gigi dan Mulut Universitas Padjadjaran untuk keperluan perawatan saluran akar pada giginya. Pasien lalu dirujuk ke instalasi radiologi kedokteran gigi untuk dilakukan pemeriksaan radiografi panoramik. Setelah diperoleh hasil radiografnya, ternyata ditemukan secara insidental suatu gambaran radiopak welldefined, berbentuk membulat pada periapikal gigi premolar pertama mandibula sinistra. Pada Gambar 2 tampak lesi tersebut tepat melekat pada 1/3 apikal akar gigi (tipe apikal) tetapi tidak memperlihatkan pola resorpsi eksternal pada akar gigi yang terlibat dengan posisi lesi masih tampak di bagian superior kanalis mandibularis. Pasien dikonfirmasi tidak ada keluhan pada gigi yang terlibat. Berdasarkan pola dan ciri radiografis yang terlihat berupa massa radiopak dengan sedikit perbedaan densitas pada area tengah lesi pada bagian periapikal gigi, tampak terpisah dari tulang trabekula, berlokasi di periapikal gigi tapi tidak meresorpsi akar gigi, dan cenderung tidak terlihat pinggiran radiolusen pada perifer lesi maka kasus ini diradiodiagnosiskan sebagai dense bone island.

Kasus kedua dilaporkan seorang pasien perempuan berumur 32 tahun datang ke poliklinik gigi sebuah rumah sakit umum untuk keluhan utama gigi area kanan rahang bawah terasa sakit saat digunakan mengunyah dan gusi terasa 


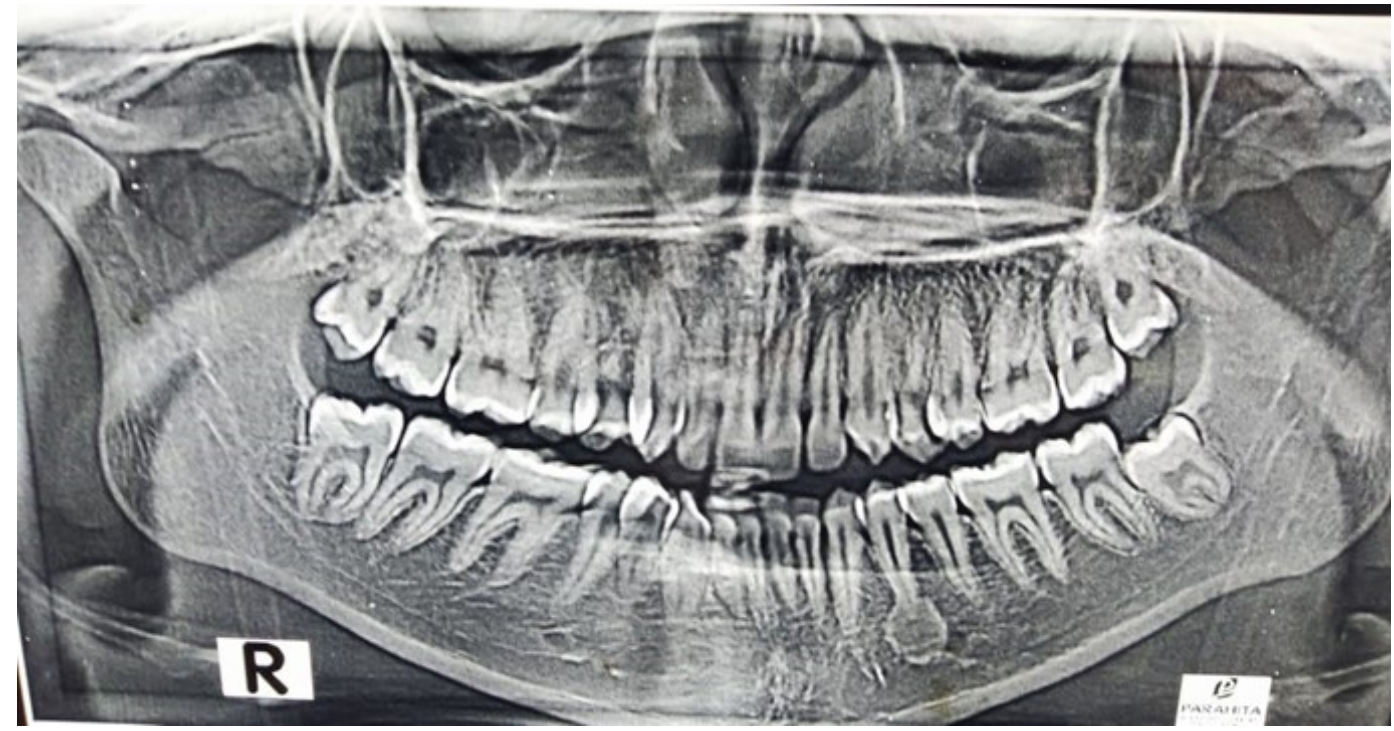

Gambar 2. Radiograf panoramik dengan lesi Dense Bone Island tipe apikal tanpa resorpsi akar

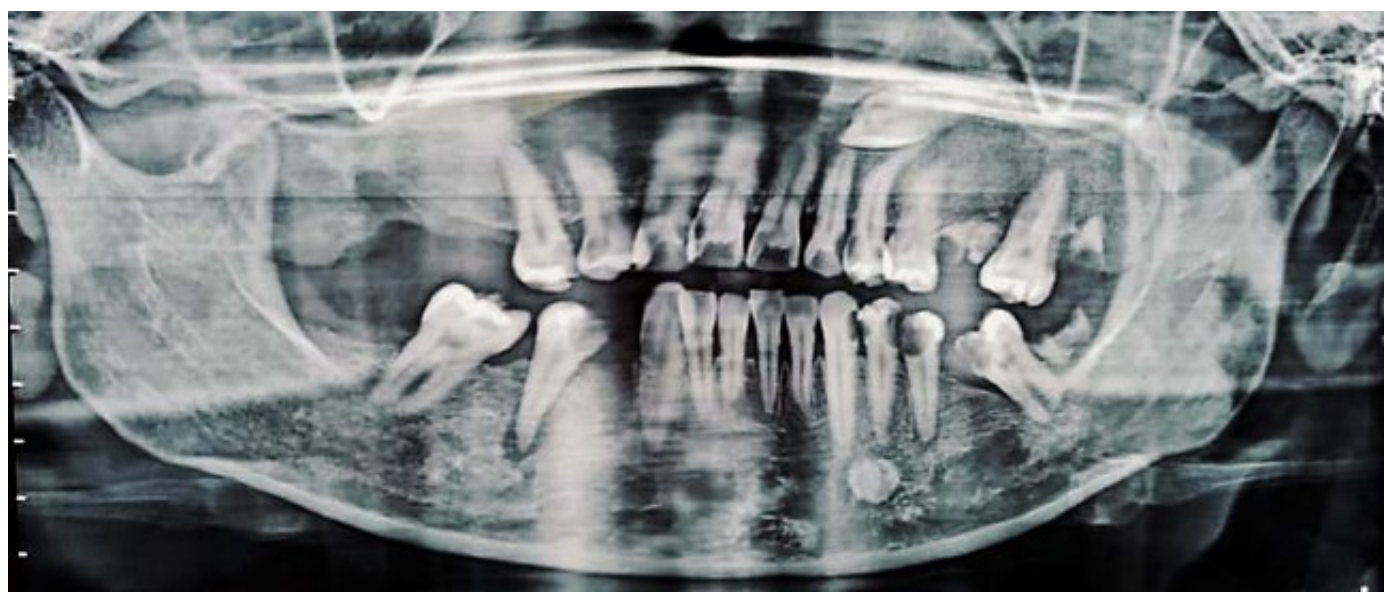

Gambar 3. Radiograf panoramik dengan lesi Dense Bone Island tipe separated

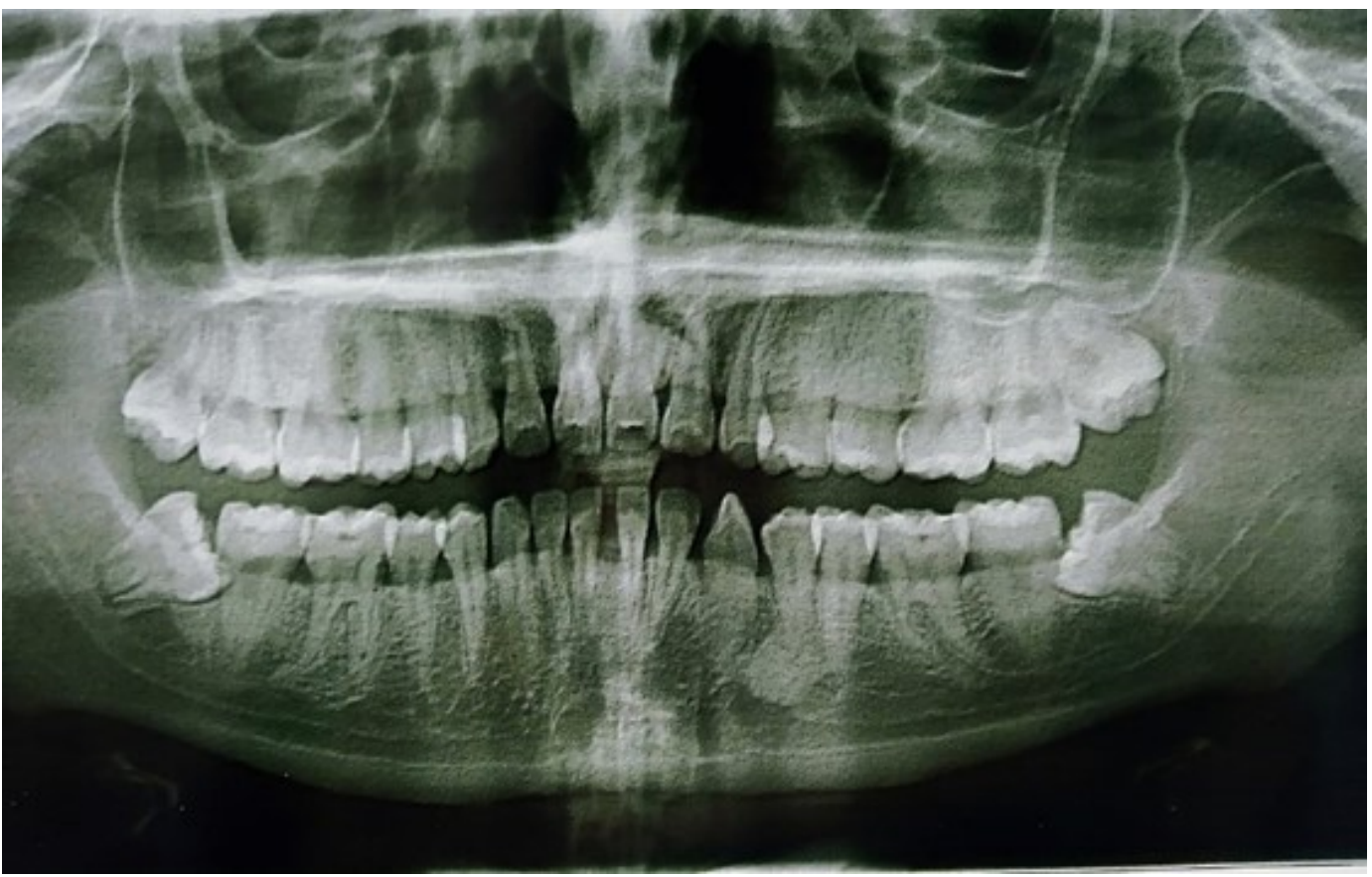

Gambar 4. Radiograf panoramik dengan lesi Dense Bone Island tipe apikal dan interadikuler 
bengkak. Pasien lalu dirujuk untuk melakukan pemeriksaan radiografi panoramik dan diperoleh hasil gigi 45 memperlihatkan abses periapikal tetap selaln itu ditemukan pula lesi radiopak berbentuk bulat tanpa tepi raidolusen pada bagian periapikal antara gigi 33 dan 34 dengan posisi jauh di bagian inferior apeks gigi (tipe terpisah) dan masih superior dari kanalis mandibularis (Gambar 3). Pasien tidak merasakan gejala apapun pada area tersebut serta tidak berhubungan dengan keluhan utama pasien pada saat dilakukan pemeriksaan radiografi. Berdasarkan ciri radiografis dan keterangan klinis kasus ini diradiodiagnosiskan sebagai dense bone island.

Sedangkan pada kasus ketiga dilaporkan bahwa seorang pasien perempuan berumur 18 tahun datang ke poliklinik gigi sebuah rumah sakit umum untuk melakukan perawatan ortodonti. Pasien dirujuk ke instalasi radiologi untuk dilakukan pemeriksaan radiografi panoramik dan hasilnya ditemukan secara insidental gambaran radiopak well-defined berbentuk membulat yang tampak menyatu dengan tulang trabekula dan tidak memiliki tepi radiolusen pada periapikal gig premolar pertama di antara gigi kaninus mandibula sinistra (tipe apikal dan interadikuler). Pada Gambar 4 tampak lesi tersebut berada pada 1/3 apikal akar mesial dan akar gigi yang terlibat tampak menjadi tidak terlalu jelas dan tampak sedikit superimposis dengan dinding superior kanalis mandibularis. Pasien dikonfirmasi tidak ada keluhan pada gigi yang terlibat. Kasus ini kemudian diarahkan pada suspek dense bone island.

\section{DISKUSI}

Laporan kasus ini mengamati adanya lesi radiopak asimptomatik yang ditemukan pada tiga pasien yang telah dilakukan pemeriksaan radiografi panoramik untuk kebutuhan tertentu. Lesi-lesi ini ditemukan secara insidental dan diradiodiagnosiskan sebagai dense bone island (DBI) atau lesi osteosklerosis periapikal idiopatik. Diagnosis ini diperoleh dari temuan radiografis tersebut serta didukung oleh tidak adanya gejala penyerta dan perluasan lesi. Ketiga pasien tidak memiliki keluhan apapun pada gigi-gigi dan processus alveolaris di area yang memperlihatkan lesi. Tidak terkaitnya lesi DBI dengan penyakit inflamasi, proses displasia, neoplasma, keterlibatan manifestasi penyakit sistemik jelas terlihat pada ketiga kasus.

Ketiga kasus terlihat pada area mandibula tepatnya pada area premolar pertama dan premolar kedua. Ketiga pasien dengan temuan lesi ini berjenis kelamin perempuan dengan usia dewasa antara 18-32 tahun. Hal ini sesuai dengan literatur-literatur yang menyebutkan bahwa lesi ini lebih sering terjadi pada usia dewasa dan beberapa penelitian yang memperoleh gambaran prevalens berdasarkan jenis kelamin menunjukkan pada perempuan lebih sering terjadi.

Secara radiografis, ketiga kasus memperlihatkan bentuk lesi yang cenderung bulat atau lonjong, dengan struktur internal radiopak yang tampak homogen pada dua kasus, dan satu kasus lainnya tampak ada sedikit perbedaan homogenitas radiopak pada bagian lesi berupa bagian-bagian yang sedikit radiolusen. Ketiga kasus juga tidak memperlihatkan adanya tepi atau margin radiolusen maupun kapsul yang memisahkan lesi dengan tulang sekitarnya. Lesi tampak berbatasan langsung dengan tulang. Berdasarkan posisi spesifiknya, ketiga kasus juga memperlihatkan posisi sesuai lima klasifikasi lokasi DBI yaitu tipe apikal pada kasus pertama dengan lesi tampak tepat berada pada apeks akar gigi 34 tetapi tidak terlihat adanya resorpsi eksternal pada akar gigi di mana lamina dura dari gigi tersebut masih dapat tervisualisasi. Tipe terpisah (separated) terlihat pada kasus kedua di mana lesi berada jauh dari apeks akar dan tampak tidak memengaruhi kanalis mandibularis, sedangkan tipe ketiga memperlihatkan jenis apikal-interadikuler di mana lesi terletak pada apeks akar gigi 34 sedikit ke arah lateral di antara gigi 33. Pada kasus ketiga lamina dura akar gigi 34 sulit divisualisasi, tapi kepastian lesi tersebut telah meresorpsi akar atau tidak perlu diperiksa lebih lanjut melalui teknik radiografi tiga dimensi untuk memastikan adanya efek pada jaringan sekitar. Posisi lesi dan hubungannya dengan kanalis mandibularis juga lebih dapat dievaluasi melalui radiograf tiga dimensi tersebut.

Dari segala informasi yang bisa didapat pada hasil radiograf panoramik ketiga pasien pada laporan kasus ini serta tidak adanya gejala klinis yang menyertai lesi maka radiodiagnosis DBI atau lesi osteosklerosis periapikal idiopatik dapat dipastikan dengan cukup baik. Diagnosis banding seperti periapical osseus dysplasia, sementoblastoma, hipersementoma, dan sclerosing osteitis dapat dikeluarkan dari tampilan radiografis lesi ini sesuai dengan kekhasan lesi-lesi tersebut.

\section{SIMPULAN}

Temuan insidental berupa gambaran radiopak well-defined pada area periapikal gigi premolar dan molar mandibula yang sebagian besar tidak merusak gigi sekitarnya dan secara klinis bersifat asimptomatik mengarah pada diagnosis dense bone island atau lesi osteosklerosis periapikal idiopatik.

\section{DAFTAR PUSTAKA}

1. Syed AZ, Yannam S. Research: Prevalence of Dense Bone Island | CCED. 2017; (October).

2. Farhadi F, Ruhani MR, Zarandi A. Frequency and pattern of idiopathic osteosclerosis and condensing osteitis lesions in panoramic radiography of Iranian patients. 2016;322-6.

3. Tolentino EDS, Cardia GS, Cristina L, Iwaki V. Idiopathic Osteosclerosis of the Jaw in a Brazilian Population: Retrospective Study. 2014;183-92.

4. Sisman $\mathrm{Y}$, Ertas ET, Ertas H, Sekerci AE. The Frequency and Distribution of Idiopathic Osteosclerosis of the Jaw. 2011;5 (October):409-14.

5. Ledesma $C$, María M, Jiménez $D$, Juan $F$, Hernández $C$. Idiopathic osteosclerosis in the maxillomandibular area. Radiol Med [Internet]. 2018;(November). Available from: 
https://doi.org/10.1007/s11547-018-0944-x

6. Misirlioglu M, Nalcaci R, Adisen MZ, Yilmaz S. The evaluation of idiopathic osteosclerosis on panoramic radiographs with an investigation of lesion's relationship with mandibular canal by using cross-sectional cone-beam computed tomography images. 2013;1(2):48-54.

7. Moshfeghi M, Azimi F, Anvari M. Radiologic assessment and frequency of idiopathic osteosclerosis of jawbones: an interpopulation comparison. Acta Radiologica. 2013.

8. G.Pillai K. Oral and Maxillofacial Radiology Basic Principles and Interpretation. 2016. 283-302 p.

9. Whites SC, Pharoah MJ. Oral Radiology Principles and Interpretation. 2014. 365p

10. Araki M, Matsumoto N, Matsumoto K, Ohnishi M, Honda K, Komiyama K. Asymptomatic radiopaque lesions of the jaws : a radiographic study using cone-beam computed tomography. 2011;53(4):439-44.

11. Oshima S, Suzuki J, Yawaka Y. Idiopathic osteosclerosis in the mandible associated with abnormal tooth root formation. Pediatr Dent J [Internet]. 2010;20(1):91-4. Available from: http://dx.doi.org/10.1016/S0917-2394(10)70198-1

12. Verzak Ž, Ćelap B, Modrić VE, Sorić P, Karlović Z. The prevalence of idiopathic osteosclerosis and condensing osteitis in Zagreb population. 2012;573-7.

13. Curé JK, Vattoth S, Shah FR. Radiopaque Jaw Lesions: An Approach to the Dif-. 2012;60463.

14. Augusto $C$, Poletto R, Itiberê $C$, Ignácio SA, Kuriki L, Tanaka $\mathrm{OM}$, et al. Could idiopathic osteosclerosis have correlations with palatally impacted maxillary canines ? 2013;12(2):105-8.

15. 15. Chintala L, Bhavya B, Chaitanya YC, Chaitanya PV. Dense bony islands of the maxillofacial region : A radiological study. 2017;3(4):258-60.

16. Koong B. Atlas of Oral and Maxillofacial Radiology. 2017. 101$102 p$

17. Santos B, Silva F. Differential diagnosis and clinical management of periapical radiopaque / hyperdense jaw lesions. 2017;1-21. 